\title{
RELAPSED AND BORDERLINE CASES OF TUBERCULOID LEPROSY
}

\author{
H. W. W.WB: \\ firom the J.conard Wood Laburalury, Culiom, Ihilippines
}

With the increased attention that has been given to the tuberculoid form of leprosy in recent years, the question of the ultimate outcome of cases of that class comes to the fore with increasing insistence. It is quite widely believed that their prognosis is particularly favorable, but because of the more or less frequent occurrence of relapse there is reason to inquire just how generally that is true. Some workers believe that occasional cases undergo transformation to the lepromatous form, but here again there is a question; others hold definitely that that change does not occur, while still others are uncertain because of lack of personal observation of the condition and the absence of convincing records in the literature. As will be seen, it is easy to be mistaken in this matter.

The conviction that tuberculoid leprosy is particularly benign is probably based largely upon experience with cases seen during what may be spoken of as the original phase of the process. In many of them, undoubtedly, the condition subsides permanently. In neural leprosy generally the outlook for patients with only one or a very few skin lesions is probably favorable. That, at least, has been the experience in the Philippines ${ }^{12}$, as it has been that of Cochrane with early cases in children in Ceylon and sourhern India, 3. 5. and-with particular reference to tuberculoid leprosy of Souza-Campos in Brazil 18. Furthermore the more active 
(reaction) cases of tuberculoid leprosy, though often very marked and frequently bacteriologically positive and consequently liable to be diagnosed as of lepromatous type, generally respond more favorably to special treatment than any other form of the disease, and even without treatment they habitually subside remarkably within a few weeks or months, even to the point of apparent recovery.

\section{Relapse in Tuberculoid Leprosy}

Perhaps because so many of the patients who have been observed in the original period drop from sight after they have improved, leaving behind them the impression of recovery, the question of relapse is seldom raised. Experience in the Philippines, however. indicates that it occurs not infrequently in cases that have been found bacteriologically positive, or " open." There is reason to believe that in Calcutta severe relapse must be a frequent occurrence.

Though tuberculoid cases are relatively less common in the Philippines than in some other places, there are always some of the more marked ones in the leprosaria, segregated because open. In 1936 the writer, with Rodriguez ${ }^{24}$ took under observation the ten that were then at the Eversley Childs Treatment Station in Cebu, among a total of some 700 inmates, together with two others from another group of neural cases that had been under study earlier ${ }^{22}$. This small group affords no less than seven examples of relapse (more than 50 per cent) in cases that at one time or another enjoyed a period of apparent cure.

Casc P. I). Hospitalized in 1935 with only a solitary but bacteriologically positive major tuberculoid plaque (right knee); a limited secondary papular eruption occurred later, after which improvement was steady. Paroled in 1937. One year afterward an eruption of " small, discrete, uniformly distributed macules " appeared, and the patient had to be rehospitalized. These lesions subsided but a new crop appeared later and the condition had not cleared up in I939.

Case T. E. Essentially identical with the preceding case up to a certain point, with at first a solitary plaque (left elbow) and later a limited papular eruption. Admitted in 1934, paroled in 1937. Reactivation occurred two years later, with several rather small, torpidly spreading leprids (these of minor tuberculoid grade), but rehospitalization has not been necessary.

Case A. S. A very different condition, a particularly marked reactional development, in a boy aged only Io (1936). Paroled in 1938. A few months afterward, and again in 1939, he was 
found to have a limited number of new but minor-degree lesions, not necessitating rehospitalization.

Cusc P. MI. A case of long duration, seen first in the Cebu clinic in I93I. Hospitalized in 1932 after a reaction, with very numerous lesions mostly of secondary, eruptive type. Paroled in I935. Reactivation and rehospitalization two years later, but only for a year. In 1939 he was found to have several lesions, somc new, but none positive.

Case $T . S$. This patient comes into this category because of her history or repeated generalized eruptions with intervening periods of subsidence beforc she was hospitalized in 1933, each outbreak following childbirth. After the fourth delivery and eruption the subsidence was less complete and she entered the leprosarium after still another reaction, with numerous conspicuous and extensive lesions. Not paroled until r 938 and not seen sincc; prognosis highly uncertain.

Case 1). A. A particularly discouraging case, now " borderline." Hospitalized in Manila in I927 with a solitary lesion (face), a few others developed later but subsided. Paroled in 1929. After five years of apparently complete recovery, in 1934 a reaction occurred and a few large leprids appeared, followed by a generalized papular eruption. With repeated reactions and multiple new lesions appearing and receding, he has remained in the Cebu leprosarium since then. For a time suspected of becoming lepromatous (Fig. I), the case is actually in a peculiar state of unbalance ${ }^{23}$.

Case $T$. C. An unusually active minor tuberculoid case in I933, it became converted to marked major a few months later during a severe reaction. Recession was rapid, but parole was delayed until I937. After quite two years of apparent recovery, relapse occurred abruptly in consequence of a pyogenic infection, the condition as a whole very suggestive of lepromatous transformation (Figs 2 and 3 ). This phase, and an extraordinary development that occurred later, have been reported 23,13 .

The group of cases from which these come was not a selected one except in that all had been bacteriologically positive, a more or less common occurrence among reaction tuberculoid cases everywhere. They are not, of course, necessarily representative as regards the frequency of relapse among tuberculoid cases elsewhere. Even for the Philippines they are too few to be statistically significant, and the course of events may be different among peoples of other races. They serve, however, to call attention to the uncertainty of absolute cure, at any given time, of a once open 
case of tuberculoid leprosy. The last two cases bring up the problem of the worst possible development, namely, transformation to the lepromatous form.

\section{Change of Form}

In the reactivation that may interrupt a case in the course of improvement, or in the relapse that may occur after the stage of apparent recovery has been reached, the new or reactivated lesions may be essentially of the same type as before. On the other hand they may depart more or less markedly from the previous ones. Those which are of diminished severity, as the change from the major to the minor tuberculoid variety exemplified by two of the cases cited above, are not of concern here; only the more serious developments are to be discussed.

As has been said, there are differences of opinion as to whether transformation to the lepromatous form occurs or not. On the negative side Schujman, who alone has written especially on the subject of prognosis, expressed doubt in this matter in $193^{16}$ and subsequently reached the conclusion that the change does not take place 17; he holds that cases either recover or persist as such for long periods. He believes, probably correctly, that Querangel des Essarts and Lefrou " ${ }^{11}$ who reported the change in two cases, were simply dealing with the reaction tuberculoid condition that has caused so much confusion in the past.

Tisseuil 19 has also expressed the opinion that tuberculoid leprosy does not evolve toward the lepromatous form. He speaks of it as a manifestation of cutaneous resistance comparable to lupus, and especially to lupus erythematosus.

Cochrane ${ }^{t}$ believes that the results of the lepromin test in tuberculoid reaction cases, generally held to be an indication of resistance, " makes unacceptable the view that tuberculoid leprosy may become lepromatous." * He speaks of " intermediate " cases with lesions that " simulate those of tuberculoid leprosy" but in which the lepromin reaction is negative. As a rule they recover after the manner of tuberculoid cases, he says, but occasionally one passes into the lepromatous form.

Mitsuda's group in Japan are especially convinced of the favorable significance of the positive lepromin reaction. So far as I am aware they have not reported lepromatous transformation of a tuberculoid case, the kind which they classify as " macular."

*It is generally agreed that, whereas the lepromin test is typically negative in leromatous cases, it is always positive in tuberculoid ones. The fact that the tissue-reaction found in the papule of a positive lepromin reaction is of tuberculoid nature, as is that reaction to the living infecting agent in tuberculoid rases, is regarded as significant in the present connection. 
Indeed, in a recent follow-up study of certain cases which had been tested years previously, Igarashi and Hayashi 7 indicate special interest in the lact that an ordinary (Mitsuda-positive) neural case had become lepromatous.

On the affirmative side of this question Ryrie, who among his Chinese patients at Sungei Buloh, in Malaya, undoubtedly sees more severe tuberculoid reactions than anyone else, has expressed the conviction ${ }^{14}$ that the tuberculoid condition is not a manifestation of resistance but a "potentially dangerous sensitization "-it represents tissue resentment to the presence of the infecting organism rather than tissue defence. The extreme ulcerative or sloughing reaction condition that he has described 15 he speaks of as a " tissue mania," adding that if the underlying factor in that condition is to be considered as resistance " it is resistance so violent and overdone that it damages the patient and often prepares the way for the transition to cutaneous leprosy." That change, he writes, has occurred in many of his cases, though it must be said that none of those that I biopsied with him in I937, some of them old, had done so at the time though some of the specimens showed a mixture of tuberculoid and lepromatous histology.

Lowe, who in the Calcutta clinic sees more acute tuberculoid cases than anyone else, leads the affirmative, having touched repeatedly on this matter. He first said 8 that, on the whole, the existence of tuberculoid lesions is evidence of high resistance and comparatively few cases become lepromatous, though he wrote later 15 that the change happens in perhaps 25 to 30 per cent of tuberculoid cases. Recounting observations in Burma ${ }^{9}$ he said that a considerable number of cases showed manifestations that ' were either 'reacting' tuberculoid lesions in which smears showed an abnormally large number of bacilli, or else were lepromatous lesions developing from a previously existing tuberculoid lesion "; and he also spoke of lepromatous cases that had lesions so peculiar in localization, distribution and otherwise that they must originally have been tuberculoid. These cases, difficult to classify, he like Cochrane speaks of as " intermediate," a term that has been used so commonly that it lacks particularity.

As for the morphology of converted lesions, he has said that sometimes the tuberculoid one forms the center of a lepromatous infiltration, the change starting at the margin and at first remaining localized here. When the process becomes marked, however, the original leprid subsides to remain as a depressed area in a "typical leproma " teeming with bacilli, and later the lepromatous condition may affect the skin of the whole body. This description might apply to the picture of a supposed leproma arising 
from a residual tuberculoid leprid that Muir has recently published 10 , except that he laid stress on a supposed lepromatous development in the flattened center of (as well as, it is gathered, around) the site of the original lesion. In that instance, he stated, there were also numerous lepromatous macules in previously unaffected skin. As will be seen, these descriptions and the picture referred to are, in the main, very similar to those of the " relapse tuberculoid "' lesions that have been observed in Cebu ${ }^{23}$ but that subsequent events proved not to be lepromatous.

Occasionally, here and there, I have run across cases with lesions of this general type-supposedly lepromatous ones abruptly delimiting sharply outlined flat areas but, in striking contrast, tending to taper off toward and to diffuse into the surrounding normal skin. Such a lesion is decidedly at variance with the typical leproma, which do not undergo central resolution and recession, and also with typical tuberculoid leprids, in which retrogression from the active marginal zone to the healed center is gradual while, in contrast, the outward limit is sharp.

A definite clue to the explanation of this peculiar formation came from the patient D.A. mentioned in I938, in one of the four special annual examinations that have been made of that case, there were found several lesions of that description, two on the forearms and two on the wrists (Fig. I). The patient, an exceptionally intelligent man, explained that the unaffected areas were the sites of previous (major tuberculoid) macules. Those areas were "immune" to the new development, but there was a striking and as yet unexplained peculiarity in their evidently intimate relation to the new, active lesion.

The nature of the active process was uncertain, but the patient refused biopsy. The bacteriological findings were not particularly suggestive, smears being reported as only $2+$ (possible maximum $4+)$. Evidence was forthcoming when, four months later, the patient agreed to biopsy: the lesions referred to had all subsided most surprisingly, while others of similar nature had arisen elsewhere. One of the latter was biopsied, but as the specimen was lost in transit its histology remains unknown. Nevertheless, the rapid subsidence of the first lesions mentioned and development of new ones, they also to disappear completely within the next few months, is significant. Only lesions that are essentially of tuberculoid lepridic nature, whatever their actual histological structure may be, can come and go like that. The case, therefore, had not gone lepromatous, nor has it done so yet; in fact a specimen obtained in 1939, when a new eruption of quite different appearance was present, proved to be tuberculoid in structure.

An exceptional demonstration of relapse tuberculoid leprids 


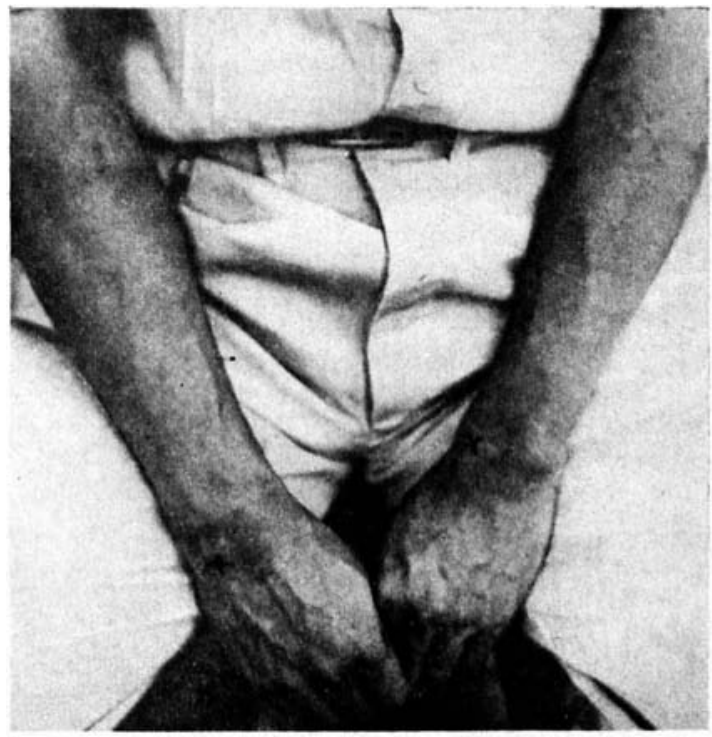

Fig. I.

"Relapse tulerculoid" lesions on wrists and upper forearms, of suspicious appearance and generally sloping off like lepromata (Case D.A.). Each wrist lesion is indented at one place $(X, X)$ by an "immune" area previously affected by an ordinary major tuberculoid leprid, and, less clearly clemonstrated, there are central immune areas in the lesions on the forearms.

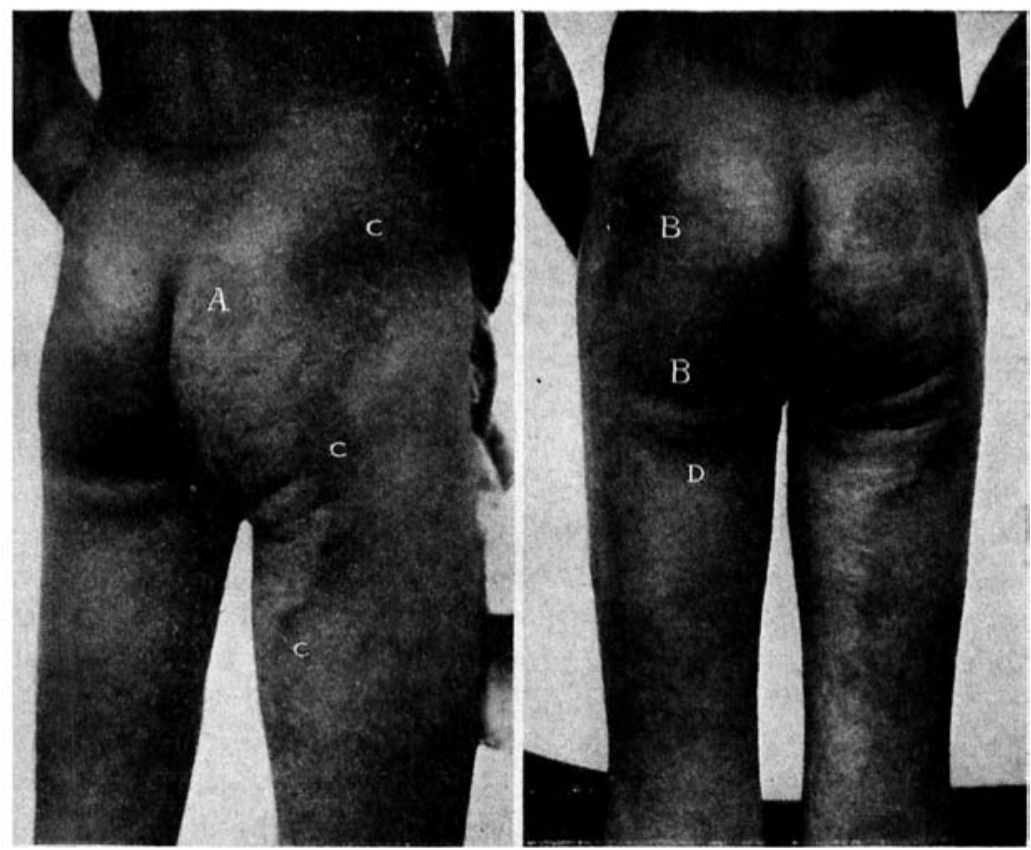

Figs. 2 and 3 .

R(markally extensive relapse tulserculoid lesions in Case T.C., showing the alorupt limitation against previously tuberculoid immune areas $(\Lambda, B, C, D)$ and diffusion above. 
was seen in the last of the cases of relapse detailed above (T.C.), when the disease suddenly became reactivated after a free period of two years ${ }^{23}$. The several extensive lesions are exemplified by those shown in Figs. 2 and 3 . The characteristic diffusion into previously unaffected skin, present in the upper part of the region, is not well demonstrated, but the abrupt margination against immune areas is conspicuous. It is seen around the rounded flat area on the right buttock (A), and also around the much larger one that covers and extends below the left buttock $(B, B)$. It is most striking on the right hip and thigh $(\mathrm{C}, \mathrm{C}, \mathrm{C})$, where previously there had been a wide and very long tuberculoid plaque. The conspicuous elevated band below the left gluteal fold occupies a narrow zone upon which the previous lesions of the buttock above and the thigh below (D) had not encroached.

The clinical and histological evidence regarding the nature of this new development was conflicting. Though it was not definitely lepromatous in appearance, some of the smears were strongly positive $(3+$; one from the nasal septum $4+$ ) and sections of a biopsy specimen showed what I can still only interpret as a nonfoamy lepromatous granuloma. In spite of that finding however, subsequent events proved that the case itself had not undergone lepromatous transformation. When the patient was hospitalized some ten weeks later all of these lesions, except certain parts of them that had been reactivated later, had subsided. In a third reaction shortly afterward a very extensive bullous condition ("leprous pemphigus") developed that resulted in extensive scarring 13. In I939 none of the lesions showed any activity, and a biopsy specimen from one of the scarred areas showed slight but definite tuberculoid change.

In this connection note may be made of a case from the literature, reported by Arning and Nonne in I893 ', which they had studied with respect to nerve changes. The patient was a youth of Dutch parentage born in Sumatra. The disease had begun several years previously with " pemphigus," followed later by " typical rings and spots of lepra maculosa." Later " nodular infiltrations" developed, and when seen by the authors there were on all the extremities extensive "lepromas " of the appearance shown by pictures that are reproduced here (Figs. 4 and 5). On the trunk and parts of the extremities there were no " real lepromas " but leprids, dark liver-brown spots, in part elevated 3 to $5 \mathrm{~mm}$. The thickest areas, on the buttocks and thighs (D), were spoken of as " large brown leprids." In spite of his condition the patient felt well and was of normal weight for his age. Significantly, the mucous surfaces were not involved.

This case is an example, the only one that I have found 

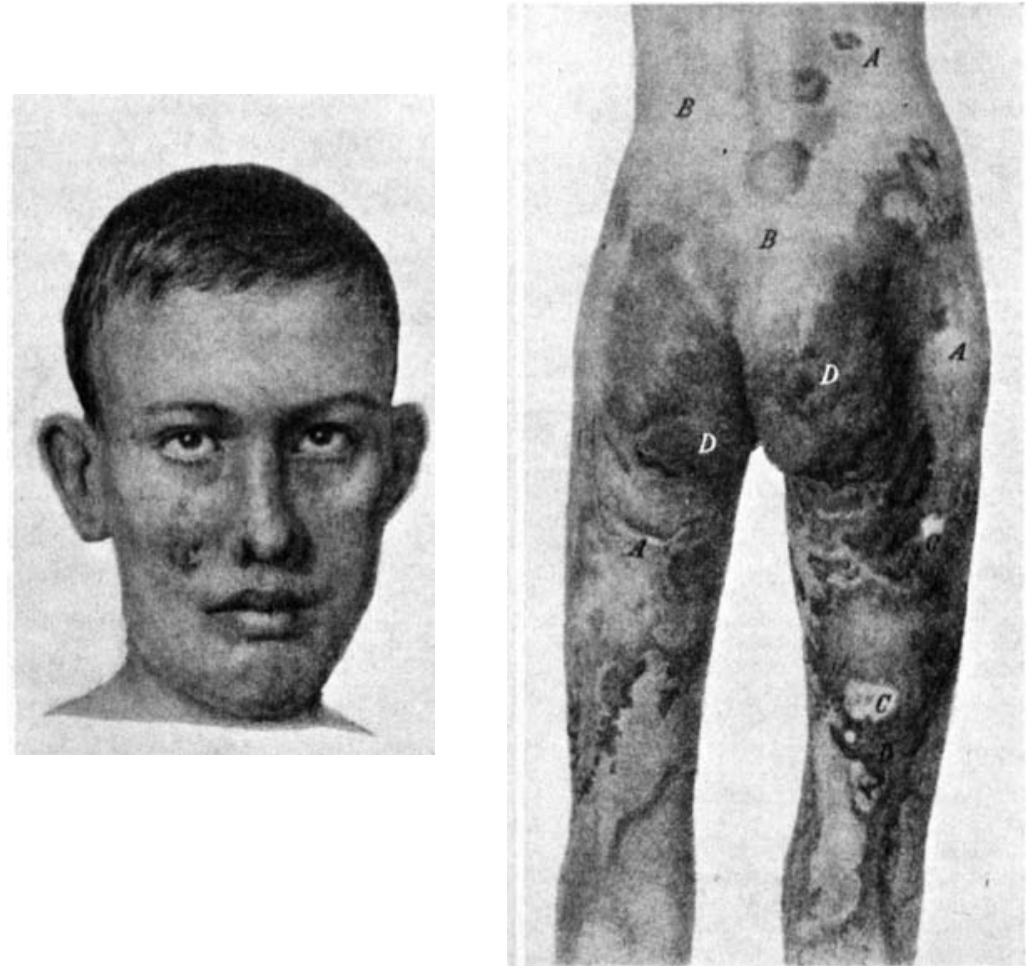

Figs. 4 and 5 .

A so-called " tubero-macular" case reported by Aming and Nonne in 189.3 (reproduced from Virchon's Archits). Evidently a marked and chronic relapse tuberculoid case.

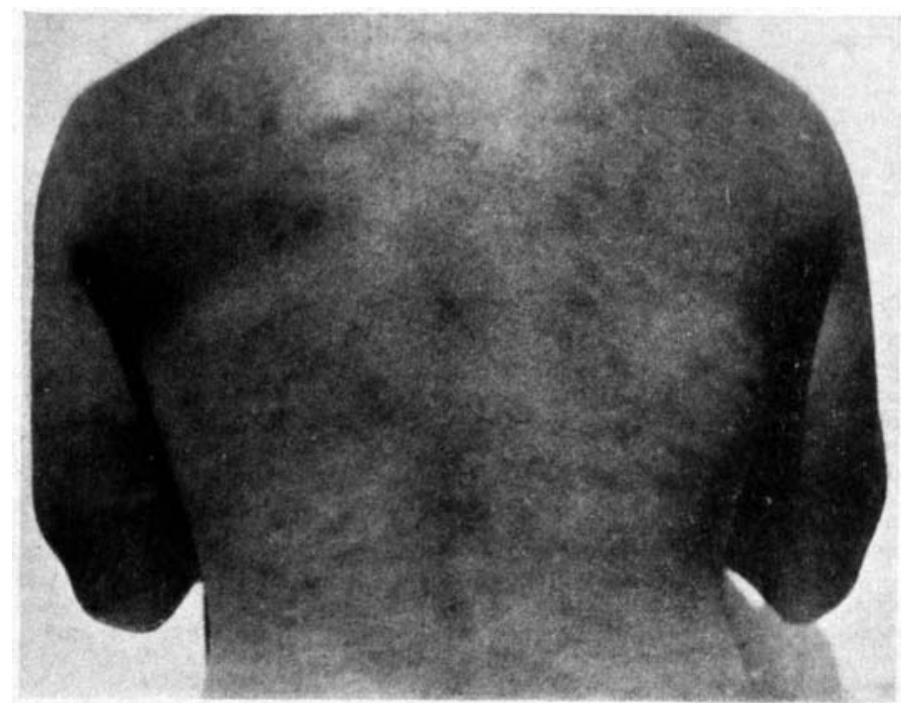

Fig. 6.

Multiple papular eruption of a persistently "borclerline" case at Celu (L.A.). Recent papules, pale residua of older ones, and areas of discoloration due to locial injection of such lesions. 
pictured, of what was then called the "tubero-macular " form. That class has long since been forgotten, but evidently it must be reinstated in the picture of leprosy but with a different concept of its nature. It seems obvious that it was one of "relapse tuberculoid " type, the lesions essentially like but more complicated and much more chronic than those in Case T.C., described. The authors recognized that certain uninvolved areas (marked C) had been affected previously, and it seems highly probable that other large areas that are sharply outlined by the new lesions had also been involved. Apparently a secondary eruption had developed inside some of these immune areas, as in Muir's photograph that has been mentioned.

Another report that may be mentioned is a recent one by de Castro Cerqueira 2 of so-called " mixed leprosy", with inter-related-shown by photographs to be in places interlocking, like parts of a jig-saw puzzle as in Case T.C.- -achromic macules and lepromas. Previous macular lesions had subsided, leaving pale residual areas; but new elevated ones had recently appeared on all parts of the body. These last were looked upon as lepromas and a biopsy specimen from one was so diagnosed, but they seem indubitably to have been of the relapse tuberculoid type. The most interesting finding in this case is that the lepromin test was positive in the flat macular areas but negative in the " nodular" lesions and in apparently healthy areas, leading the author to lay emphasis on local variations of reactivity of the skin.

The personally studied cases here cited certainly do not cover the field of atypical lesions that may be taken for leprids transformed to lepromata; it may be, perhaps, that their lesions are not representative of the most common that occur elsewhere. the peculiar papular eruption that has long dominated the picture of Case A.D. (Fig. 6) and that has for quite as long been the only important manifestation of the disease in a second borderline case (Figs. 7 and 8) cannot be discussed here. It may, however, be worth while to note a peculiar borderline case seen in South China with Fraser ${ }^{20}$, though it does not exemplify the relapse tuberculoid condition.

There were lesions of three quite different aspects: (a) Conspicuous infiltrations of lepromatous appearance, particularly on the face and ears (Fig. 9). (b) A group of small, oval patches on the neck, sharply delimited and abruptly elevated, the surface level but coarsly granular, of tuberculoid aspect (Fig. 9). Bacilli in smears varied from absent to fairly numerous. (c) Multiple expanding lesions, evidently eruptive but of unusual appearance, on the thighs (Fig. Io) and elsewhere. Though merging had often produced complex figures, the typical unit 


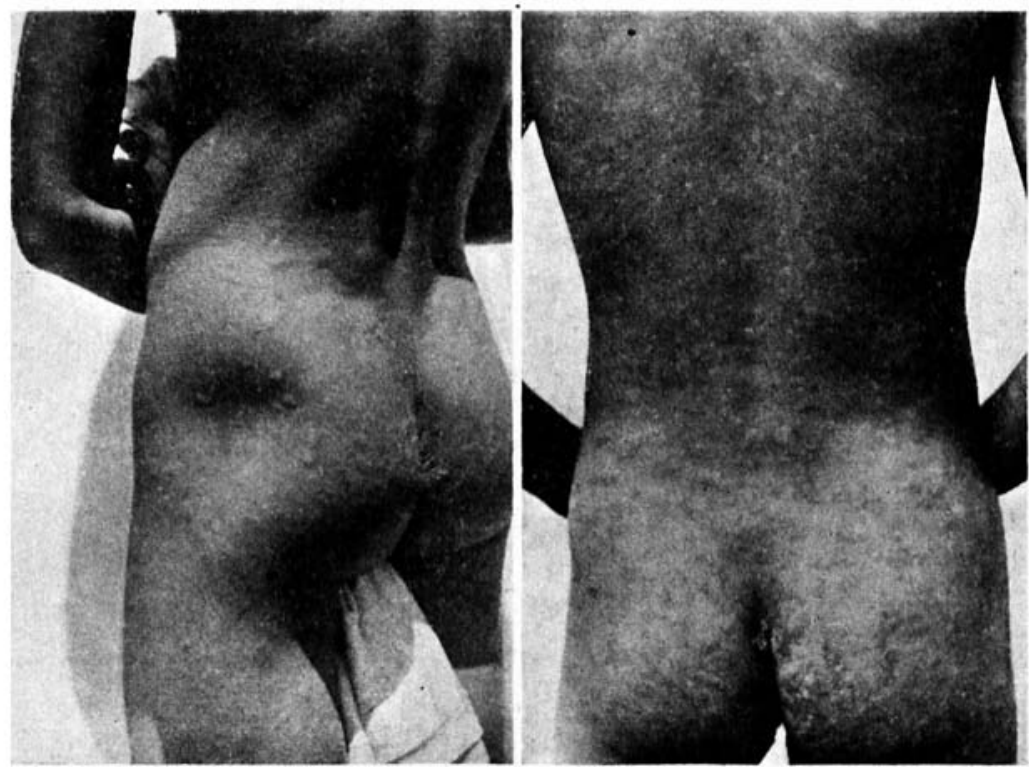

Figs, 7 and 8 .

Multiple papular eruption of another horderline case, the first showing the typical flat tuberculoid papules early in the course (1936), the second showing the condition later (1938) with, among other lesions, many residual ones with hyperchromic halos resulting from local injections.
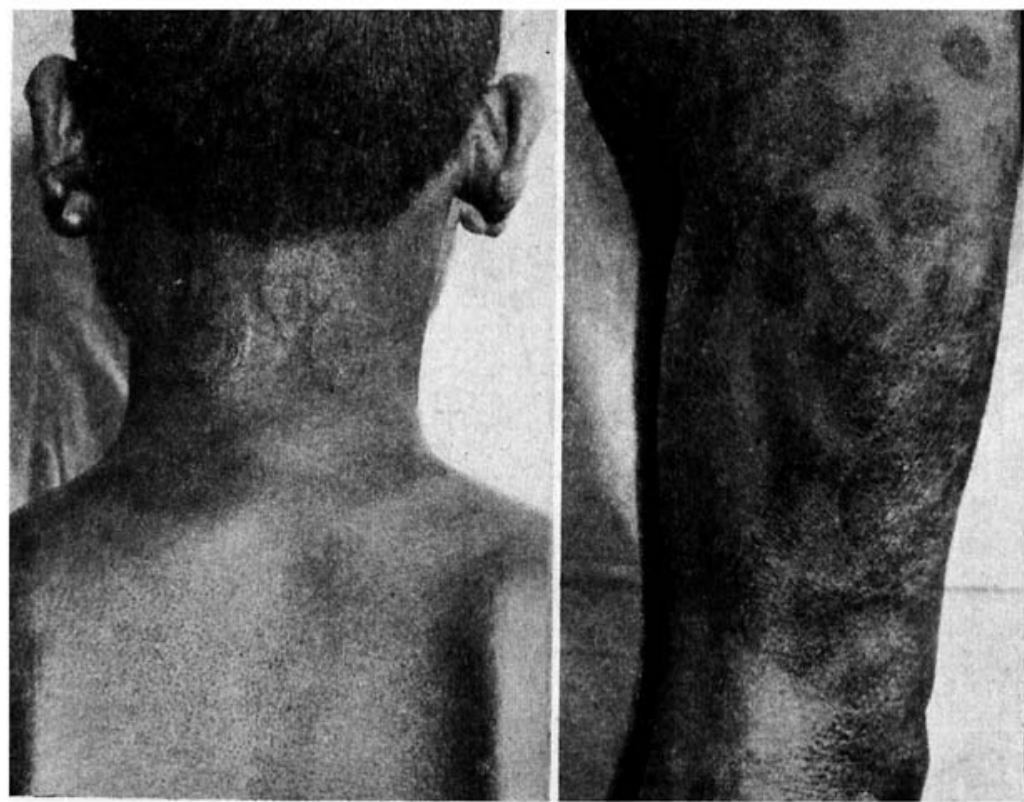

Figs. 9 and ro.

Showing the supposed lepromatous condition of the ears, the small tuberculoid plaques on the neck, and apparently intermediate lesions of the thighs in a borderline case seen in China. 
lesion was a rather smali round, moderateiy elevated, dully crythematous macule, soon becoming annular after the manner of ordinary leprids. In places, however, there were confluent areas that did not show this retrograde change but were highly suggestive of lepromatous infiltration (sec Fig. Io, near knec). Furthermore, the outer edges of all of them sloped off to the normal skin (though not diffusing as completely as do lepromata); and smears were strongly positive, with occasional small globi. A biopsy specimen from one of the patches on the neck showed in part definite tuberculoid changes but mostly an atypical granuloma suggestive of a nonvacuolate leproma. One from the thigh showed only the latter condition.

Here, then, was a case with apparently lepromatous lesions (face and ears), a few that were clinically tuberculoid (neck), and many of a more or less intermediate appearance (as on the thigh). These manifestations, together with the bacteriological findings suggested that the condition was a mixed one, transitional from tuberculoid to lepromatous. The process did not continue in that direction, however, for a few months later the lesions had subsided markedly, the face returning to approximately normal appearance; the ultimate outcome is not known. The case may be looked upon as borderline, differing considerably from the persistent ones studied in Cebu but no less difficult to classify.

\section{Commen't}

The cases cited serve to show, if nothing else, that transformation from the resistant, tissue-reactive (" allergic ") tuberculoid form of leprosy to the anergic lepromatous form is a thing not easily accomplished, that the influences which determine the essential nature of the tuberculoid form are not easily abolished. A case may seem to have gone far in that direction, as regards the morphology of the lesions, their bacteriological content, and even their histology, to say nothing of the response to the lepromin test, yet will be proved by its subsequent course not to have become lepromatous in its actual character. That such cases may be mistakenly thought to have undergone transformation is not surprising, especially when it is considered that it has not been so long since we have come to recognize as tuberculoid, instead of Jepromatous, the more ordinary bacteriologically positive major tuberculoid cases in reaction.

That transformation of such cases may occur it would be rash to deny. It is greatly to be hoped, however, that those who have the opportunity of observing the phenomenon will report in detail, with data on the clinical, bacteriological, histological and immunological changes, cases that have been followed through their 
course. From the experiences here related it is obvious that follow-up observations are absolutely indispensable, for one thing to eliminate those borderline cases which subsequently clear up after the manner of ordinary reaction tuberculoid cases, for another thing to ascertain what those that persist indefinitely in the borderline state may come to look like, and yet again to learn if those that actually undergo transformation take on the aspect and follow the course of ordinary lepromatous leprosy. In the meantime, it is evident that caution is in order in pronouncing a case transformed.

\section{Summary}

The question of the prospect for absolute cure, or on the other hand that of transformation to the lepromatous type, of active major tuberculoid cases, especially those that at one time or another have been found bacteriologically positive, is discussed.

Out of twelve such cases observed at Cebu for several years, no less than seven have relapsed at one time or another after apparently complete recession of the disease. In one instance there had been a period of five years without trouble. It is suggested that the feature of relapse in tuberculoid leprosy is worthy of more attention than it has received.

Lepromatous transformation has not as yet occurred in any of these cases. Two of them, however, have persisted for three years and more in an unstable, "borderline" condition, the picture dominated by repeated papular eruptions, the lesions atypical clinically and histologically. Another borderline case of decidedly different aspect seen in China is cited; it presented at the same time apparently lepromatous, tuberculoid and intermediate lesions and was looked upon as transitional, yet later recession occurred as is common in ordinary tuberculoid leprosy.

At one time in one of the two persistently borderline cases at Cebu, and in a third one when it relapsed after two years of apparent recovery, there have been lesions of a kind designated " relapse tuberculoid," more or less suggestive of lepromatous development both morphologically and bacteriologically, and also histologically in the one specimen examined. These lesions look not unlike lepromata, especially with respect to their tendency to taper off to and diffuse into the adjacent normal skin; and in

* Since this manuscript was prepared there has come to hand an article by Davy 6 in which he emphasizes the need of careful and repeated clinical study of cases. He mentions borderline cases as a field for investigation and describes a condition, supposedly lepromatous, which seems very likely to be essentially of the nature of the persistentlv borderline cases studied at Cebu, though apparently the former condition differs in the progression of the eruptive lesions. 
contrast with the gradual central recession of typical tuberculoid leprids they typically surround or adjoin, the infiltration ending abruptly, "immune" areas which are the sites of previous tuberculoid lesions. The subsequent course of the disease in both cases has shown conclusively that they had not undergone lepromatous transformation, but that the lesions were essentially of lepridic character.

Two reported cases of apparently similar nature are cited, one recent and one old , of the form then called " tubero-macular ". Such reports, and other evidence from current literature, afford reason to believe that lesions of this atypical " relapse tuberculoid " kind have at times been accepted as evidence of lepromatous change.

Experience indicates that there may exist the paradoxical situation of a case with lesions that, so far as can be identified by known,criteria, are histologically lepromatous but that may behave clinically like ordinary tuberculoid lesions. Therefore, disconcerting as it may be, the histological findings cannot always be regarded as diagnostic in atypical cases of the kind under consideration. The situation is further complicated if, as seems to be the case, the lepromin reaction may be negative.

The conclusion is obvious that transformation of a tuberculoid case is not readily accomplished, and that caution must be exercised in diagnosing it. This matter, especially, calls insistently for careful investigation.

\section{REFERENCES}

1. Arning, E. and Nonne. Weiterer Beitrag zur Klinik and Anatomic der Neuritis leprosa. Virch. Arch. 13.4 (1893) 319-330.

2. De Castro Cerqueirn,, G. Um interessante caso de lepra mista. Rev. Brasileira Leprol. o (1938) 341-352.

3. Cochrane, R. G. Recent advances in epidemiology, diagnosis and prevention of leprosy. Jour. Christian Med. Assoc., India, Burma and Ceylon 14 (1939) 236.

4. Cochrnne, R. G. The development of lesions of leprosy, with particular reference to tuberculoid leprosy and the lepromin test. Internat. Jour. Lep. 8 (1940) in press.

5. Cochrane, R. G., De Simon, D. S. and Fernando, A. G. Preliiminary observations on childhood leprosy in Ceylon. Internat. Jour. Lep. 5 (1937) 61-65.

6. DAviey, T. F. Problems for rescarch work in leprosy institutions. Lep. Rer. 11 (1940) 90-95.

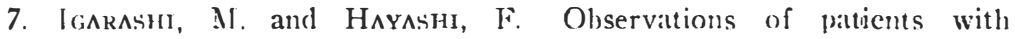
atypical Mitsuda reactions, after an interval of ten years. Internat. lour. Lep. $8(194())$ in press. 
8. Lowe, J. A note on tuherbuloid changes in leprosy as seen in India. Internat. Jour. Lep. + (1936) 195-199.

9. Lowe, J. A note on racial variations in leprosy with particular reference to Indian and Burmese races. J.ep. in Indic 10 (1938) 132-139; also Indikn Med. (idw. 73 (1938) 591-595.

10. Nuir, E. Resistance and the typing of leprosy skin lesions. Lep. Rev. 10 (1939) 221-225.

11. Querangei, Des Essarts, J. and Lefrou, G. Evolution des léprides en lépromes. Bull. Soc. Palk. exot. 29 (1930) 945-949.

12. Rodrigurz, J. N. and W'Ade, H. W. The status after five years of neural leprosy cases studied in Cebu. Internat. Jour. Lep. 7 (1939) 309-326.

13. Ronriguez, J. N. and Waif, $H . W^{\prime}$. Bullous tuberculoid leprosy; report of cases, with discussion of lazarine leprosy. lnternat. Jour. Lep. 8 (1940) in press.

14. Ryrie, G. A. The treatment of tuberculoid leprosy. Lep. Rev. 9. (1938) 51-55.

15. Ryrif, G. A. Acute ulcerative or sloughing tuberculoid leprosy. Internat. Jour. Liץ. 6 (1938) 153-159.

16. Schujman, S. (lassification and evolution of tuberculoid leprosy. Internat. Jour. Lep. 4 (1936) 369 and 375 (correspondence).

17. Schuman, S. Evolución'y prognostico de la lepra tuberculoide. (Eestudio realizado en 100 casos vigilados de 2 a 10 años.) Rev. Brasileira Leprol. 7 (1939) 1-25.

18. Souza-Campos, N. Aspects cliniques de la lèpre tuberculoide chez l'enfant. Rez: Brasileira Leprol. 5 (1937) Spec. No.. pp. 99-113.

19. Tissfuil, J. Ie l'ćvolution et de la classification de la lèpre tuberculoide. Bull. Soc, Path. exot: 31 (1938) 803-800.

20. Wade, H. W. and Fraser, N. I). The skin lesions of neural leprosy' III. Observations in (hina. Internat. Jour. Lep. 5 (1937) 285-308

21. Wade, H. W. and Lows, J. The type distribution of patients at the Purulia Leper Colony. Lep. in India 9 (1937) 39-48 (footnote J.L.).

22. Wade, H. W. and Ronkiguez, J. N. Development of major tuberculoid leprosy; a report of cases. Internat. Jour. Lep. 7 (1939) 327-340.

23. W'ane, H. W'. and Ronriguez, J. N. Borderline tuberculoid leprosy. Internat. Jour. Lep. $\delta$ (1940) in press.

24. Waine, H. W', Ronkigif., J. N. and Tolentino, J. G. The course of open cases of tuberculoid leprosy at the Cebu leprosarium. Internat. Jour. Lip. 7 (1939) 473-494. 